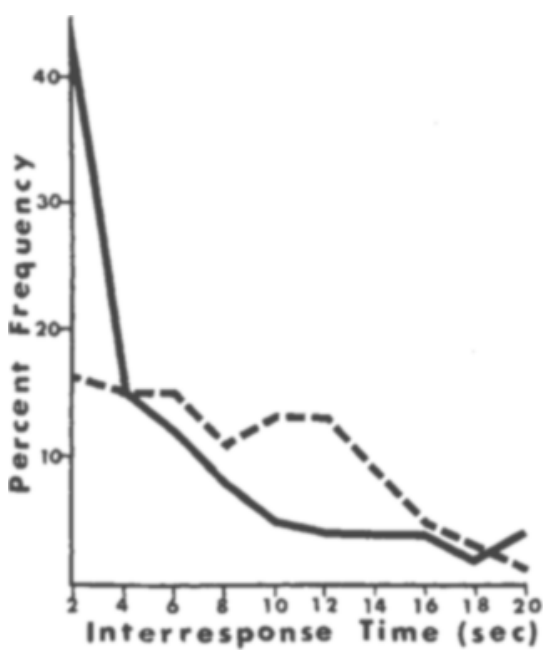

Fig. 2. The per cent frequency distributions of the time between successive responses (interresponse time) averaged over the last 5 days of training for a representative $\mathbf{S}$ with a septal lesion (broken line) and a control $S$ (solid line). The frequencies are plotted at the upper limit of the $2-\mathrm{sec}$ interval.

that the Ss with septal lesions performed the free-operant avoidance task more efficiently than did the control Ss by virtue of their enhanced ability to delay successive responses.

Figure 2 further demonstrates the enhanced response inhibition of the experimental Ss. This figure illustrates IRT distributions of the avoidance responses for a representative $S$ from each group averaged over the last 5 days of training. The modal point of the distribution for the control $S$ remained in the 0 to 2 -sec IRT interval and constituted $42 \%$ of the avoidance responses. While the modal point for the experimental $\mathrm{S}$ was also in the 0 to $2-\mathrm{sec}$ interval, it constituted only $16 \%$ of the avoidance responses. The median of the IRT distribution for the control $S$ was $3.1 \mathrm{sec}$ while the median for the experimental S was $6.7 \mathrm{sec}$. The IRT distribution of the experimental S in Fig. 2 shows the formation of a secondary peak in the 8- to $10-\mathrm{sec}$ and $10-$ to $12-\mathrm{sec}$ IRT intervals. The individual IRT distributions of the last 5 days which were averaged to form the distribution shown in Fig. 2 also indicated this secondary peak in the same intervals. The formation of the secondary peak in these intermediate intervals indicates a more rapid development of a temporal discrimination and, thus, more efficient performance in the experimental Ss than in the control Ss.

Boren, Herrnstein, \& Sidman (1959) found that for individual Ss, increasing levels of shock lead to increased rates of responding on a reinforcement schedule similar to the one used in this study. This would indicate that the Ss with septal lesions are not responding with lower rates due to an increase in shock sensitivity.

Therefore, whether considering initial acquisition or long-term performance, the rats with lesions in the septal area learned the task faster and reached a higher level of performance than the control Ss. The experimental group received fewer shocks but demonstrated a lower response rate and enhanced response inhibition. It has been hypothesized that the septal area mediates response inhibition in the intact animal. In view of our results, it seems that this interpretation is not sufficient to cover the entire range of phenomena observed following damage to the septal area.

\section{REFERENCES}

BOLLES, R., \& POPP, R. Parameters affecting the acquisition of Sidman avoidance. Journal of the Experimental Analysis of Behavior, 1964, 7, 315-321.

BOREN, J. J., SIDMAN, M., \& HERRNSTEIN, R. J. Avoidance, escape, and extinction as functions of shock intensity. Journal of Comparative \& Phy siological Psychology, 1959, $52,420-425$.

ELLEN, P., \& POWELL, E. W. Temporal discrimination in rats with rhinencephalic lesions. Experimental Neurology, 1962, 6, 538-547.

ELLEN, P., WILSON, A., \& POWELL, E. Septal inhibition and timing behavior in the rat. Experimental Neurology, 1964, 10, 120-132.

McCLEARY, R. A. Response specificity in the behavioral effects of limbic lesions in the cat. Joumal of Comparative \& Physiological Psychology, 1961, 54, 605-613.

McCLEARY, R. A. Response-modulating functions of the limbic system. Initiation and suppression. In E. Stellar and J. M. Sprague (Eds.), Progress in physiological psychology. New York: Academic Press, 1966.

SIDMAN, M. Avoidance conditioning with brief shock, and no exteroceptive warning signal. Science, 1953, 118, 157-158.

NOTE

1. Supported in part by Biomedical Sciences Support Grant FR-07036 from the National Institutes of Health. The senior author holds a predoctoral traineeship, GM-1362, from the National Institute of General Medical Sciences.

\title{
A pheromone associated with social dominance among male rats'
}

LESTER KRAMES, W. J. CARR, and BRIAN BERGMAN, Temple University, Philadelphia, Pa. 19122

Forty male rats, living in 10 groups $(N=4$ per group), with stable dominance hierarchies preferred the odor from submissive strange males over that from dominant strange males $(p<.05)$. The response to the two odors was not significantly related to $\boldsymbol{S}_{\boldsymbol{s}}$ rank in their hierarchy. Fourteen males from four unstable hierarchies $(N=3-4$ per group) preferred neither odor. The data suggest the existence of a releaser pheromone associated with social dominance in rats.

Olfaction is known to play an important role in the regulation of agonistic behavior among both wild and domestic rats (Rattus norvegicus). If reared from weaning in small groups, males of either variety live in reasonable harmony-the domestic rats by establishing a linear and transitive hierarchy (Baenninger, 1966) and the wild rats a stratified organization consisting of three classes, with members of each class treating each other approximately as equals (Barnett, 1964). In both varieties, high ranking residents readily attack adult male intruders, but not adult females or young (Grant \& Chance, 1958; Runyon \& Turner, 1964; Barnett, 1964). Attacks are preceded by olfactory investigation, especially of the intruder's genitalia. Males of lower rank are less likely to attack intruders, but the presence of an intruder causes an increase in "recognition sniffing" among residents (Barnett, 1964). If members of two isolated groups of wild rats can smell each other through a barrier, they do not fight when placed together (Barnett, 1967, p. 98). Thus, a "group" odor may inhibit aggression.

Runyon \& Turner (1964, pp. 78-81) reported that adult male intruders usually are forced to the bottom of a hierarchy of domestic rats, but occasionally a particularly aggressive intruder may cause the residents to assume postures of defeat before fighting occurs. These workers suggested that the residents may respond to the appearance or the odor of the aggressive intruder. Therefore, the present experiment was performed to determine whether domestic rats react differentially to the odors from strange dominant vs submissive males and whether S's rank in its hierarchy influences its reactions to the two odors. SUBJECTS

AND ODORANT ANIMALS

Seventy-two male rats of the Long-Evans strain were housed as weanlings in 18 groups of four rats each. Fourteen groups provided 54 Ss (2 died before testing) and the remaining four groups provided the domi- 
nant and submissive males serving as odorant animals during testing. All animals were housed in cages measuring $14 \times 15 \times 28$ in. They were made of hardware cloth and the floors were covered with sawdust. The animals lived in an air-conditioned room in which the day-night cycle was reversed. They had constant access to Purina lab chow and water until they were 7.5 months old at which time they were maintained on a $22-h$ food deprivation schedule for the remainder of the experiment.

\section{DOMINANCE TESTING}

Beginning 2 weeks after the food deprivation schedule was introduced, the dominance hierarchy within each cage was ascertained by recording the relative amount of time each $S$ spent controlling a food cup from which only one rat at a time could feed. The Ss were allowed to eat dry mash for $2 \mathrm{~h}$ per day from a $4-0 \mathrm{z}$ cup fastened to the center of the front wall of each living cage. The cap of the cup contained a 1.75 -in. diam hole and when the cup was one-fourth filled with mash only one rat at a time could put its head through the hole and eat. A wire mesh screen placed on top of the mash prevented $S$ from carrying food away.

Once a week for 8 consecutive weeks, Es recorded the number of seconds each $S$ spent controlling the food cup during a dominance test consisting of the first $20 \mathrm{~min}$ of the 2-h feeding period. An $\mathrm{S}$ was said to be in control of the cup while its head extended through the hole of the cup. At the end of each dominance test, $S$ s in each cage were ranked from first (i.e., the dominant animal) to fourth, in terms of the relative time each $S$ spent controlling the food cup.

The first 2 weeks of the dominance testing procedure were treated as a training period during which $S s$ adjusted to the restricted feeding conditions; the last 6 weeks were treated as the test proper. Within cages, a hierarchy was considered stable only if all Ss each held a constant rank during at least five of the last six weekly tests and 11 of the 18 cages met this criterion. Three cages which did not meet the criterion, but which contained a clear-cut dominant $S$, received three additional tests with the dominant $\mathrm{S}$ absent. Of these, two cages then yielded stable hierarchies. In the third cage it was necessary to remove both the first- and second-ranked Ss in order to establish the identity of the third and fourth. Four of the 18 cages failed to meet the criterion during a total of 17 tests.

\section{ODOR PREFERENCE TESTING}

One week after the completion of dominance testing, each $\mathrm{S}$ was tested individually for its response to the odors from a pair of strange males, one of which was dominant (Rank 1) and the other submissive (Rank 4). The testing situation was similar to that described by Carr, Loeb, \& Dissinger (1965,p. 371, Fig. 1). The test was conducted in S's home cage and consisted of three 10-min periods, each separated by $24 \mathrm{~h}$.

During a test period, Es recorded the number of seconds $S$ spent investigating two cylindrical cardboard containers attached to the rear corners of S's home cage. The containers, measuring $4 \times 8$ in., had earlier housed for $1 \mathrm{~h}$ either a dominant or submissive strange male. Holes in the caps at either end of the containers allowed for the passage of odor-laden air into S's cage, but $S$ could not enter the containers. A $4 \times 4$ in. cylindrical cardboard atrium was attached to each container and $S$ was said to be investigating a given odorant if any part of its head extended inside the atrium. A counterbalancing procedure was used to eliminate the effects of a possible position preference on the part of Ss.

Four pairs of male rats served as odorant animals to which Ss responded. Each pair consisted of the first and fourth ranked animal from 1 of the 14 cages yielding stable hierarchies. Thus, the odorant animals were novel to $S s$ in the 14 remaining cages (10 with stable and 4 with unstable hierarchies). The use of four pairs of odorant animals avoided confounding individual male odor with that reflecting the odorant animal's rank in its hierarchy.

\section{RESULTS AND DISCUSSION}

Table 1 shows the mean time Ss spent

Table 1

Time Spent Investigating Dominant vs Submissive Male Odors Ss from 10 Stable Groups ( $N=4$ per Group) Mean Investigation Time (in sec)

\begin{tabular}{lccccc}
\hline $\begin{array}{l}\text { S's Rank } \\
\text { In Group }\end{array}$ & N & $\begin{array}{l}\text { Dominant } \\
\text { Male Odor }\end{array}$ & $\begin{array}{l}\text { Submissive } \\
\text { Male Odor }\end{array}$ & $\begin{array}{l}\text { Difference } \\
\text { Score }\end{array}$ & $\begin{array}{l}\text { Preference } \\
\text { Ratio }^{\mathbf{a}}\end{array}$ \\
\hline First & 10 & 49.1 & 75.4 & -26.3 & $1 / 9$ \\
Second & 10 & 50.1 & 42.0 & +8.1 & $4 / 6$ \\
Third & 10 & 39.5 & 55.2 & -15.7 & $3 / 7$ \\
Fourth & 10 & 45.3 & 54.7 & -9.4 & $3 / 7$ \\
All Ranks & 40 & 46.0 & 56.8 & $-10.8 *$ & $11 / 29$ \\
& & Ss from four Unstable Groups (N = 3-4 per Group) & $5 / 9$ \\
All Ranks & 14 & 38.4 & $\mathbf{4 5 . 5}$ & -7.1 & \\
\hline
\end{tabular}

a The preference ratio is defined as the number of Ss preferring the dominant male odor divided by the number preferring the submissive male odor.

$*<.05$ investigating the two odorants during the 30-min preference test, together with their mean difference score (dominant minus submissive). The $40 \mathrm{Ss}$ from the 10 cages yielding stable hierarchies spent more time investigating the submissive than the dominant male odor and their observed individual difference scores departed significantly from chance expectancy (Wilcoxon matched-pairs, signed-ranks test, $\mathrm{T}=225$, $\mathrm{N}=40, \mathrm{p}<.05$ ). Therefore, males from stable hierarchies prefer the odor from strange submissive males over that from strange dominant males. Although $\mathrm{Ss}$ that ranked first in their hierarchies responded more consistently than did Ss ranked lower (see preference ratios), none of the four subgroups from stable hierarchies showed a significant preference for either odor. The 14 Ss from the 4 cages yielding unstable hierarchies showed a slight and nonsignificant preference for the odor from strange submissive males.

The present findings indicate that male rats can discriminate between the odors from dominant vs submissive strange males. The findings also suggest the existence of a releaser pheromone (Wilson \& Bossert, 1963; Gleason \& Reynierse, 1969) reflecting the strange animals' social rank in their hierarchy. The odor from strange dominant males releases withdrawal behavior on the part of other males, as compared with their response to the odor from strange submissive males. However, the releaser may be more effective on males living in stable social hierarchies than on males living in unstable hierarchies.

\section{REFERENCES}

BAENNINGER, L.P. The reliability of dominance orders in rats. Animal Behaviour, 1966, 14, 367-371.

BARNETT, S. A. Social stress. In J. D. Carthy and C. L. Duddington (Eds.), Viewpoints in biology. Vol. 3. London: Butterworths, 1964 Pp. 170-218.

BARNETT, S. A. Instinct and intelligence. Englewood Cliffs, N.J.: Prentice-Hall, 1967.

CARR, W. J., LOEB, L. S., \& DISSINGER, M. L. Responses of rats to sex odors. Journal of Comparative \& Phy siological Psy chology, 1965, $59,370-377$.

GLEASON, K. K., \& REYNIERSE, J. H. The behavioral significance of pheromones in vertebrates. Psychological Bulletin, 1969, 71 , 58-73.

GRANT, E. C., \& CHANCE, M. R. A. Rank order in caged rats. Animal Beháviour, 1958, 6, 183-194.

RUNYON, R. P.,\& TURNER, W. J. A study of the effects of drugs on the social behavior of white rats. Greenvale, N.Y.: The Research Center of C. W. Post College, 1964

WILSON, E. O., \& BOSSERT, W. H. Chemical communication among animals. Recent Progress in Hormone Research, 1963, 19, 673-716. NOTE

1. This investigation was supported by Public Health Service Research Grant HD 00345 from the National Institute of Child Health and Human Development. 